\title{
Physical Properties in Aqueous Solutions for a Series of Alkyltrimethylammonium Salicylates (C12TA-Sal through C16TA-Sal): From a View Point of Drag Reduction
}

\author{
Yasushi Yamamoto ${ }^{*}$, Takashi Arai ${ }^{1}$, Takashi Tomita1, Zameer Shervani1 ${ }^{*}$, Akihiro Yoshino $^{1}$, \\ Keijiro Taga ${ }^{*}$, Shinji Tamano', Motoyuki Itoh1, Yoshitaka Taguchi² \\ ${ }^{1}$ Graduate School of Engineering, Nagoya Institute of Technology, Nagoya, Japan \\ ${ }^{2}$ Chukyo Yushi Co. Ltd., Nagoya, Japan \\ Email: ^yamamoto.yasushi@nitech.ac.jp, „zameer.nitec@gmail.com, ^taga.keijiro@nitech.ac.jp
}

How to cite this paper: Yamamoto, Y., Arai, T., Tomita, T., Shervani, Z., Yoshino, A., Taga, K., Tamano, S., Itoh, M. and Taguchi, Y. (2016) Physical Properties in Aqueous Solutions for a Series of Alkyltrimethylammonium Salicylates (C12TASal through C16TA-Sal): From a View Point of Drag Reduction. Soft Nanoscience Letters, 6, 45-55.

https://doi.org/10.4236/snl.2016.64005

Received: August 10, 2016

Accepted: September 15, 2016

Published: October 31, 2016

Copyright $\odot 2016$ by authors and Scientific Research Publishing Inc. This work is licensed under the Creative Commons Attribution International License (CC BY 4.0).

http://creativecommons.org/licenses/by/4.0/

\begin{abstract}
Compounds for a series of alkyltrimethylammonium salicylates (C12TA-Sal through C16TA-Sal) were synthesized. Their physical properties in aqueous solutions were investigated by conductometry, viscometry, vortex inhibition, viscoelastic recoil and swirling decay time from a view point of drag reduction. For critical micelle concentrations (CMC) obtained for a series of compounds by conductometry, it was found that a linear relation of the form, $\log (\mathrm{CMC})=4.088-0.305^{\star} \mathrm{Nc}(\mathrm{Nc}$ : carbon number in the alkyl chain), holds. From the viscosity measurement, all the compounds showed viscosity increase above their CMC. Vortex inhibition was observed above the CMC for the compounds with the chain length longer than C13. Viscoelastic recoil was observed above the concentration of one and a half times the CMC for the compounds with alkyl chain length longer than C14.
\end{abstract}

\section{Keywords}

Drag Reduction, Vortex Inhibition, Viscoelastic Recoil, CMC

\section{Introduction}

Drag reduction or Toms effect is a flow phenomenon in which a reduction in turbulent friction occurs by the addition of a small amount of polymer or surfactant into a turbulent flow. The drag reduction in pump work was shown to be almost more than $60 \%$ which may provide significant savings for electric power or in energy use. Thus, much 
attention is focused in this field [1] [2] [3] [4]. Rheological properties of polymers and surfactant solutions are similar in the drag reduction. However, polymers in solution were broken by mechanical stress such as in pump, while in surfactant solution, micelles are reassemble into micelles after being degraded. Therefore, surfactants have been utilized in a district's heating and cooling systems to reduce pumping power in Japan [4] [5] [6].

As for screening of the surfactant for the drag reduction, vortex inhibition and viscoelastic recoil were used. When pure water in a beaker is stirred by a magnetic stirrer, a vortex forms and reaches the bottom of the beaker. After addition of a testing surfactant in the beaker, if the solution becomes viscoelastic, the vortex will disappear. This phenomenon is called vortex inhibition and used for the screening [7] [8]. While, when a test solution in a beaker is stirred by a magnetic stirrer and the stirrer is stopped, the solution will slows down in the direction of the swirling motion. If the solution is viscoelastic, it will stop, then, swirl in the opposite direction [9]. This phenomenon is written in some studies as recoil of bubbles [10] [11] [12], elastic recoil [13], or recoil phenomenon [14] [15]. However, as for a keyword of elastic recoil or recoil phenomenon, it has another meaning in medical term which means the rebound of the lungs after having been stretched by inhalation. Furthermore, there is another term of elastic recoil detection which refers to as forward recoil scattering in a nuclear technique in materials science to obtain elemental concentration depth profiles in thin films. Thus, avoid the confusion in the present phenomenon in the viscoelastic surfactant solution, we will use a new term of "viscoelastic recoil".

For major part of the drag reducing agents, mixtures of cationic surfactants and organic counterions have been used; especially the mixture of hexadecyltrimethylammonium bromide (cetyltrimethylammonium bromide; C16TAB, CTAB) and sodium salicylate (SalNa). Authors in the present study (Itoh and Tamano) have reported the velocity measurement in turbulent boundary layer by use the mixture of C16TAB/ SalNa [16].

Since aqueous solution of the mixture of $\mathrm{C} 16 \mathrm{TAB} / \mathrm{SalNa}$ is a ternary system, Gravsholt has reported the pioneering work of binary system (C16TA-Sal and water) without $\mathrm{NaBr}$ together with the homologous isomers of organic counterion [10]. She also has studied the properties of C16TA-Sal by using Linear Dichroism spectroscopy [17] and rheopectic behaviour [18]. Following her report, Angel et al. have studied the physical properties for even carbon number ATA-Sals (C10-C16) in aqueous solutions [19]. Imae et al. [20] [21] [22] and Hashimoto et al. [23] have reported the spinnability for C14TA-Sal and C16TA-Sal. Moreover, Imae et al. have reported the unique properties of C16TA-Sal layers adsorbed on glass beads [24]. In these studies, the origin of viscoelasticity in aqueous solution of C14TA-Sal and C16TA-Sal was ascribed to the formation of rod-like micelles. Recently, Alfaro et al. have reported the detailed analysis for the phase and rheological behaviour of the C16TA-Sal in the diluted, semi-diluted, and concentrated aqueous solutions together with the temperature dependence [25].

In the present study, we synthesized a series of alkyltrimethylammonium (ATA)Salicylates (Sal), C12TA-Sal through C16TA-Sal, including odd number of the hydro- 
carbon chain. Furthermore, we dealt with the physical properties of ATA-Sals in aqueous solutions from a view point of the drag reduction by using conductometry, viscometry, vortex inhibition, viscoelastic recoil, and swirling decay time.

\section{Experimental Section}

Materials: Compounds for a series of ATA-Sals (C12 through C16) were synthesized by an ion exchange column of IRA400J CL (Organo Co) similar to the method by Gravsholt [10] using the corresponding alkyltrimethylammonium bromide (ATAB) of C12 through C16 with Salicylic acid (Sal). The obtained compounds were recrystallized two times from acetone and small portion of ethanol. Compounds of C12TAB, C14TAB, and C16TAB were purchased from Tokyo Kasei Co. Compounds of C13TAB and $\mathrm{C} 15 \mathrm{TAB}$ were synthesized by the coupling with the corresponding $\mathrm{n}$-alkyl bromide (C13Br and $\mathrm{C} 15 \mathrm{Br}$ ) and trimethylamine, following the method of Birdi [26], respectively. The C13Br, C15Br, and Sal were purchased from Wako Pure Chemicals Co.

Purity: Purities of the ATA-Sals were checked by a portable ion meter IM-32P (TOA-DKK) for $\mathrm{Br}^{-}$. The amounts of $\mathrm{Br}^{-}$in all the ATA-Sals were less than $0.8 \mathrm{mg} \cdot \mathrm{L}^{-1}$ of the detection limit of the ion meter.

Conductometry: Conductance measurements were taken with a conductivity meter CM-40V (TOA-DKK) using CG-7001PL with cell constant of 0.0995. A surfactant was progressively added to water in a beaker placed on a magnetic stirrer, and the conductance was measured after thorough mixing and temperature equilibrium at $25^{\circ} \mathrm{C} \pm$ $0.1^{\circ} \mathrm{C}$.

Viscometry: Viscosity measurements were taken using a Ubbelohde viscosimeter (Shibata Scientific Technology Ltd) at $25^{\circ} \mathrm{C} \pm 0.1^{\circ} \mathrm{C}$. Various sample solutions were prepared in a beaker with the unit of $\mathrm{mmol} \cdot \mathrm{kg}^{-1}$ just before each experiment.

Vortex inhibition, Viscoelastic recoil, and Swirling decay time (SDT): Pure water $(200 \mathrm{~mL})$ was placed in a $200 \mathrm{~mL}$ glass beaker on a magnetic stirrer with $35 \mathrm{~mm}$ stir bar, which was kept at $1000 \mathrm{rpm}$. A surfactant was added progressively in the beaker at $25^{\circ} \mathrm{C} \pm 0.1^{\circ} \mathrm{C}$. The average depth of the vortex was measured by a ruler behind the beaker. Additionally, the phenomenon of viscoelastic recoil was also observed and SDT, which was the time between stopping the stirrer and the starting the recoil, was measured.

\section{Results and Discussion}

\subsection{Critical Micelle Concentration (CMC)}

There are so many experimental methods to obtain CMC of surfactant in aqueous solution due to the difference of monomer-micelle equilibrium, such as surface tension, electric conductivity, refraction and so on [27]. Since different experimental methods may reflect the monomer-micelle transition to different extents, we confined the experimental method to the measurement of conductivity. When conductivity is plotted against concentration, two almost straight lines are obtained and the intersection is considered to be the CMC. Figure 1 shows the conductivity-concentration for C16TA- 
Sal and the distinct break is regarded as the CMC. Table 1 shows the CMC values for a series of ATA-Sals in this study together with their mother compounds of ATABs. As for the $\mathrm{CMC}$ values for $\mathrm{ATABs}$ except for $\mathrm{C} 13 \mathrm{TAB}$, the reported values are as follows: C12TAB, 14.2 - $15.8 \mathrm{mmol} \cdot \mathrm{L}^{-1}$ [27]-[35]; C14TAB, 3.60 - $3.943 \mathrm{mmol} \cdot \mathrm{L}^{-1}$ [27]-[33] [35] [36]; C15TAB, $1.7 \mathrm{mmol} \cdot \mathrm{L}^{-1}$ only obtained by fluorimetry [35]; C16TAB, $0.81-0.9642$ $\mathrm{mmol} \cdot \mathrm{L}^{-1}$ [27]-[33] [37]. In the present study, the CMC values obtained for ATABs were good agreement with the values in the literature except for the unit of mmol. $\mathrm{kg}^{-1}$.

For C16TA-Sal, Gravsholt has reported the $\mathrm{CMC}$ value as $0.152 \mathrm{mmol} \cdot \mathrm{L}^{-1}$ at $25^{\circ} \mathrm{C}$ [10]. While, Angel et al. have reported the CMC values for C12TA-Sal, C14TA-Sal, and C16TA-Sal as $2.85,0.625$, and $0.15 \mathrm{mmol} \cdot \mathrm{L}^{-1}$ at $25^{\circ} \mathrm{C}$, respectively [19]. Furthermore, Imae et al. have reported the CMC value as 0.15 [21] [24] for C16TA-Sal and Hashimoto et al. 0.69 for C14TA-Sal and $0.10 \mathrm{mmol} \cdot \mathrm{L}^{-1}$ for C16TA-Sal at $25^{\circ} \mathrm{C}$ [23]. In the present study, the CMC value for C12TA-Sal, C14TA-Sal, and C16TA-Sal was 2.72, 0.63 , and $0.16 \mathrm{mmol} \cdot \mathrm{kg}^{-1}$, respectively (Table 1 ), indicating that these were in good agreement with the values reported in the literature.

As for the CMC for C13TA-Sal and C15TA-Sal, there are no values in the literature. However, Klevens has reported that, in a homologous series, the CMC values normally decrease logarithmically with the number of carbon atoms $(\mathrm{Nc})$ in the chain according to the following equation, $\log (\mathrm{CMC})=\mathrm{A}-\mathrm{B}^{\star} \mathrm{Nc}$, where $\mathrm{A}$ and $\mathrm{B}$ are constant specific

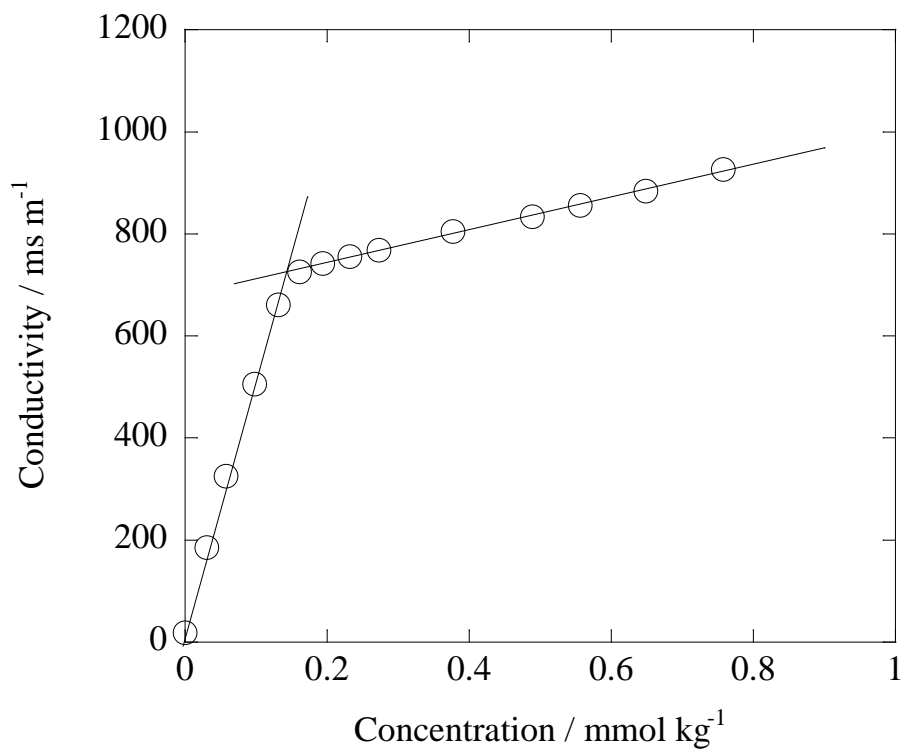

Figure 1. Concentration dependence of conductivity of C16TA-sal.

Table 1. CMC of ATAB and ATA-Sal $\left(\mathrm{m} \cdot \mathrm{mol} \cdot \mathrm{kg}^{-1}\right)$.

\begin{tabular}{cccccc}
\hline Nc & 12 & 13 & 14 & 15 & 16 \\
\hline ATAB & 15.5 & 7.6 & 3.8 & 1.9 & 0.90 \\
ATA-Sal & 2.72 & 1.32 & 0.63 & 0.34 & 0.16 \\
\hline
\end{tabular}


to a homologous series [38]. Figure 2 shows the relations between $\mathrm{Nc}$ and the CMC values for both the series of $\mathrm{ATAB}$ and ATA-Sal: ATABs, $\mathrm{A}=4.881, \mathrm{~B}=0.307$; ATA-Sals, $A=4.088, B=0.305$. It is found that, for both the series of ATABs and ATA-Sals, the slopes of B are almost the same and may be taken to be $\log 2$ with sufficient accuracy [38].

Angel et al. have reported that the conductivity-concentration plots for the systems of hexadecylpyridinium salicylate and teteradecylpyridinium salicylate, (C16Py-Sal and C14Py-Sal), showed two breaks [19]. They have concluded that the first break was the $\mathrm{CMC}$ of the systems where they begin to form micelles. Additionally, the second break was assigned to the transition concentration $c_{t}$ above which the systems form rod-like micelles. They have also reported no $c_{t}$ values for C12TA-Sal, C14TA-Sal, and C16TASal at $25^{\circ} \mathrm{C}$ [19]. However, Ohlendorf et al. have reported the CMC and $c_{t}$ at various temperatures [39]. In their report, the $\mathrm{CMC}$ and $c_{t}$ were of equal concentration at $20^{\circ} \mathrm{C}$ $\left(2.54 \mathrm{mmol} \cdot \mathrm{L}^{-1}\right)$ and $30^{\circ} \mathrm{C}\left(2.93 \mathrm{mmol} \cdot \mathrm{L}^{-1}\right)$ for C12TA-Sal and at $20^{\circ} \mathrm{C}\left(0.583 \mathrm{mmol} \cdot \mathrm{L}^{-1}\right)$ for C14TA-Sal, while at $30^{\circ} \mathrm{C}, c_{t}$ observed for C14TA-Sal $\left(1.14 \mathrm{mmol} \cdot \mathrm{L}^{-1}\right)$ and C16TA-Sal $\left(0.474 \mathrm{mmol} \cdot \mathrm{L}^{-1}\right)$. In the present study, we have observed only one break in the conductivity-concentration plots at $25^{\circ} \mathrm{C}$ for a series of ATA-Sals (Figure 1 for C16TA-Sal).

In the detailed report by Alfaro et al. [25], there are three types of critical concentrations: $c m c_{1}$, formation of spherical micelle; $c m c_{2}$, the sphere-to-prolate ellipsoidal transition; $m g c$, formation of wormlike micelle by using the electrical conductivity, surface tension, sound velocity, and Sudan II absorbance measurements. Average values for $c m c_{1}$ and $c m c_{2}$ were $3.5 \times 10^{-4}$ and $1.2 \times 10^{-3}$ (wt.\%) at $35^{\circ} \mathrm{C}$, corresponding to 0.0083 and $0.028 \mathrm{mmol}$, respectively. Their method to prepare sample solutions was the dilution of concentrated surfactant solution. In the present study, since we used the progressive addition of the sample surfactant to a solution, it was too difficult to obtain the critical concentration values of the $c m c_{1}$ and $c m c_{2}$ in these highly dilute regions (Figure 1). However, Alfaro et al. have reported the value of $m g c$ as $1.1 \times 10^{-2}$ (wt.\%), corres-

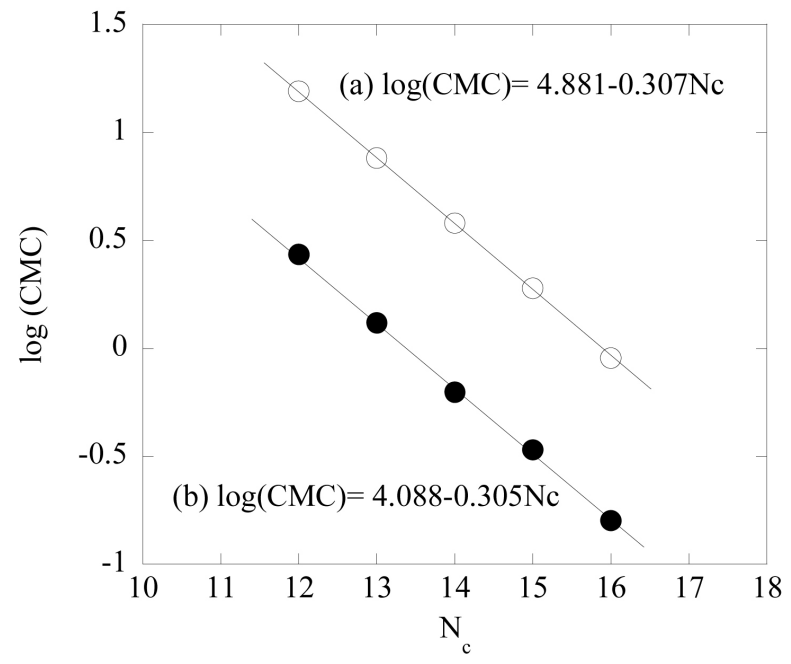

Figure 2. $\log \mathrm{CMC}$ vs crabon number: (a) ATAB, (b) ATA-Sal. 
ponding to $0.26 \mathrm{mmol}$. Especially, the $m g c$ value from the specific electrical conductivity and Sudan II absorbance was $0.7 \times 10^{-2}$ (wt.\%), corresponding to $0.17 \mathrm{mmol}$, was in good agreement with the CMC values in the present study and the previous studies [10] [19] [21] [23] [24].

\subsection{Viscosity}

Figure 3 shows the viscosity-concentration dependence for a series of ATA-Sals. The horizontal axis is the concentration in the unit of mmol. $\mathrm{kg}^{-1}$. Angel et al. have studied the viscosity for even number ATA-Sals (C12-C16) by measuring the complex viscosity with an oscillating viscometer and that the viscosity increased rapidly by several orders of magnitude [19]. This viscosity increase is ascribed to the length of the rods in a micelle. In the present study, it is found that the viscosity increased rapidly for C15TA-Sal and C16TA-Sal. However, it is hard to appreciate the relation between the viscosity and the CMC. Thus, Figure 4 shows the viscosity-concentration dependence with the normalized values divided by the respective CMC (Table 1) in the horizontal axis. The viscosity for ATA-Sals was found to change from the respective CMC. As for the compounds of the shorter chain length of C13TA-Sal and C14TA-Sal, the viscosities were gradually increased and drastically increased for C15TA-Sal and C16TA-Sal.

\subsection{Vortex Inhibition}

After addition of a testing surfactant in a beaker on a magnetic stirrer, the vortex disappeared, if the solution became viscoelastic. In this study, the compound of C12TA-Sal hardly ever showed the vortex inhibition. Figure 5 shows the height of the vortex for ATA-Sals except for C12TA-Sal for various concentrations. The horizontal axis is also normalized by the respective CMC. It is found that the vortex inhibition

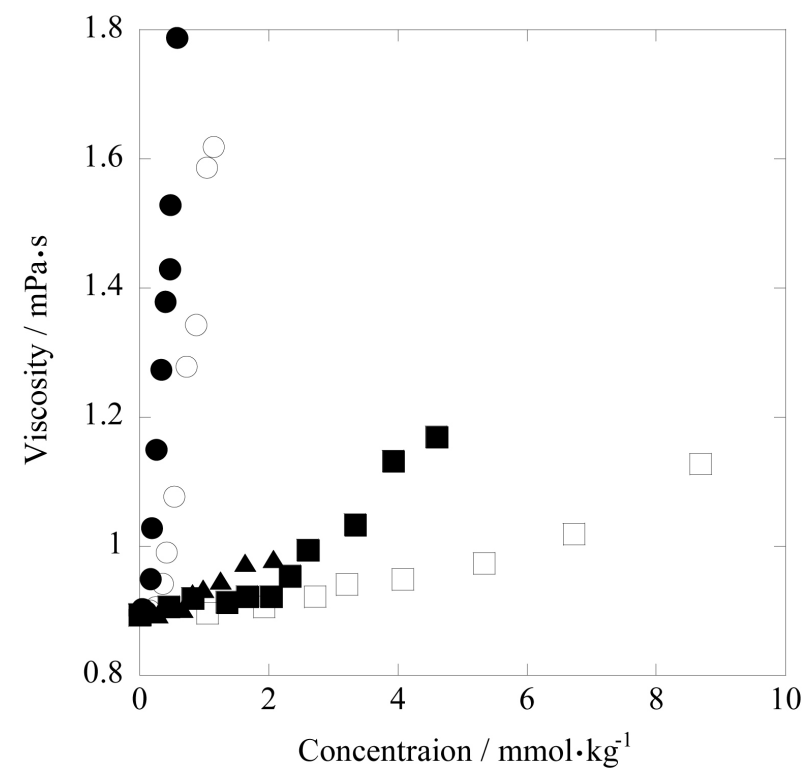

Figure 3. Concentration dependence of viscosity for ATA-Sal:

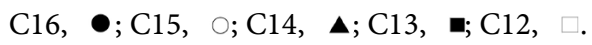




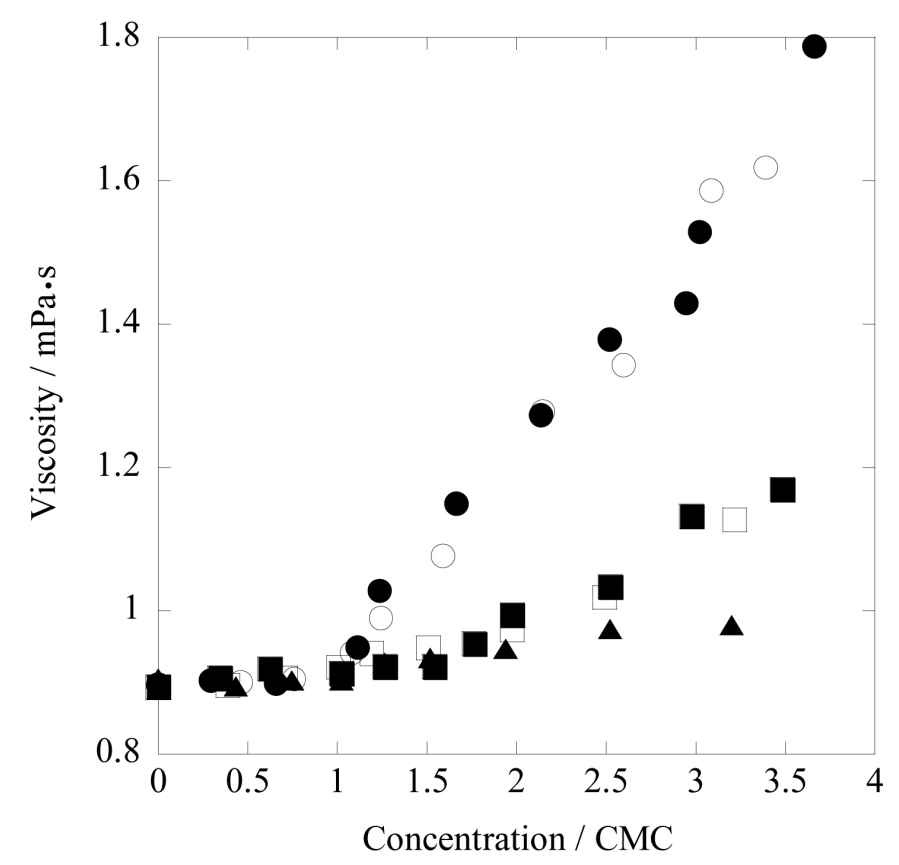

Figure 4. Concentration dependence of viscosity for ATA-Sal: C16, $\bullet ; \mathrm{C} 15, \quad$; $\mathrm{C} 14, \Delta ; \mathrm{C} 13, \mathbf{m} ; \mathrm{C} 12, \square$.

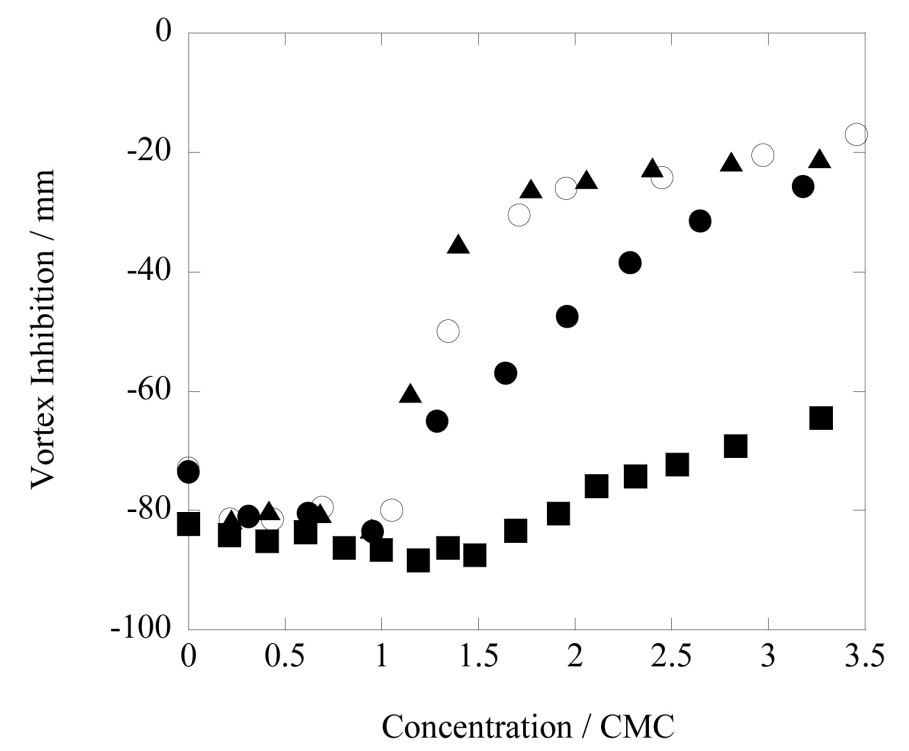

Figure 5. Vortex Inhibition for a series of ATA-Sal: C16, •; C15, $\mathrm{O}$ C14, $\mathbf{\Delta} ; \mathrm{C} 13$,

starts from the CMC for these compounds. However, for C14TA-Sal and C15TA-Sal, the vortex disappeared just above the CMC and almost constant height at around the concentration of one and half of the CMC. On the other hand, for C16TA-Sal, the vortex gradually disappeared just starting the $\mathrm{CMC}$ and almost constant height at around three times the CMC (ca. $0.50 \mathrm{mmol} \cdot \mathrm{kg}^{-1}$ ), indicating that the growth of the rods completed at this concentration starting from the CMC, not the transition concentration $c_{t}$. 


\subsection{Viscoelastic Recoil and SDT}

Viscoelasticity was detected by the method of visually observing recoil of small air bubble in a beaker after swirling was stopped [9]. Viscoelastic recoil was observed neither for C12TA-Sal nor C13TA-Sal. Figure 6 shows the SDT for C14TA-Sal, C15TA-Sal, and C16TA-Sal with the increase in concentration. The horizontal axis is also normalized by CMC, showing that the viscoelastic recoil was observed from the concentration of one and a half the CMC for these compounds and almost constant at around twice the CMC. Since the shorter the SDT the stronger the viscoelasticity, it is found that the compounds of C15TA-Sal and C16TA-Sal has the strong viscoelasticity above the concentration of twice the CMC; $0.7 \mathrm{mmol} \cdot \mathrm{kg}^{-1}$ (280 ppm) for C15TA-Sal, $0.35 \mathrm{mmol} \cdot \mathrm{kg}^{-1}$ (150 ppm) for C16TA-Sal.

\section{Conclusion}

CMC for a series of ATA-Sals showed the linearity with the number of carbon atoms $\left(N_{c}\right)$ in the chain according to the equation, $\log (\mathrm{CMC})=\mathrm{A}-\mathrm{B}^{\star} \mathrm{N}_{c} ; \mathrm{A}=4.088, \mathrm{~B}=$ 0.305. Additionally, transition concentration $\left(c_{t}\right)$ from spherical micelle to rod-like micelle was not observed for these compounds. In case of viscosity, the value for C15TA-Sal and C16TA-Sal drastically increased with increase in concentration above the CMC, while the compounds of the shorter chain length below C14 gradually increase. For the compounds with the longer alkyl chain of C14TA-Sal, C15TA-Sal, and C16TA-Sal showed the vortex inhibition starting from the CMC. These compounds showed the viscoelastic recoil and the almost constant SDTs were observed for C15TA-Sal and C16TA-Sal above the concentration of twice the CMC. Thus, it is reconfirmed that C16TA-Sal is the most suitable compound for drag reduction from the

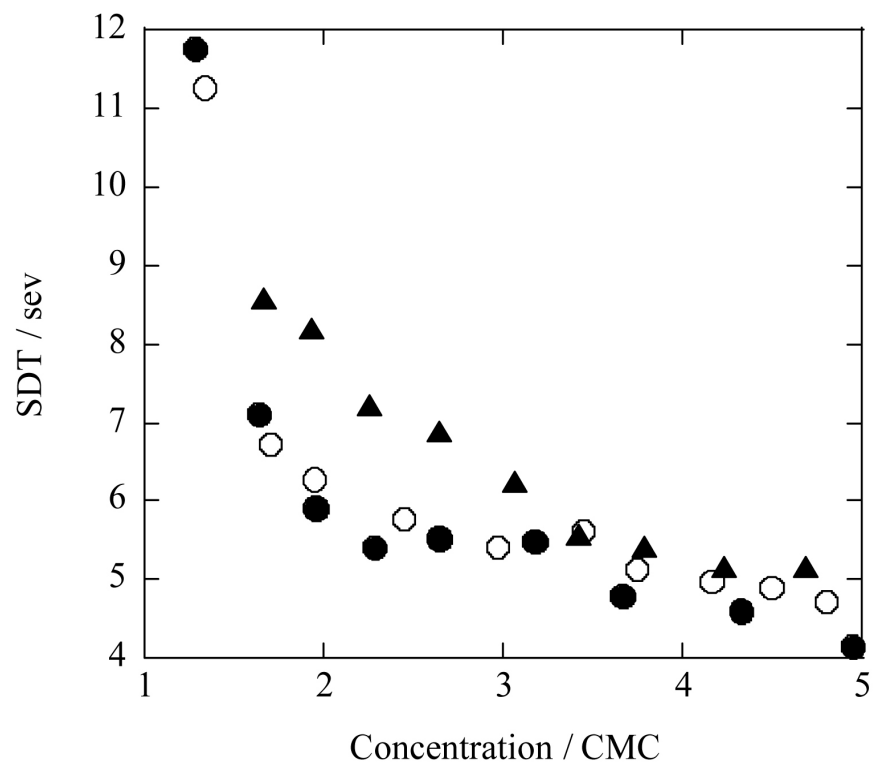

Figure 6. Swirl Decay Time for a series of ATA-Sal: C16, •; C15, $\circ \mathrm{C} 14$, 
view point of both the characteristic property and the concentration in diluteness.

\section{References}

[1] Virk, P.S. (1975) Drag Reduction Fundamentals. AIChE Journal, 21, 625-656. https://doi.org/10.1002/aic.690210402

[2] Bewersdorf, H.-W. and Ohlendorf, D. (1988) The Behaviour of Drag-Reducing Cationic Surfactant Solutions. Colloid and Polymer Science, 266, 941-953. https://doi.org/10.1007/BF01410851

[3] Gyr, A. and Bewerddorff, H.-W. (1995) Drag Reduction of Turbulent Flows by Additives. Kluwer Academic Publishers, Dordrecht/Boston/London. http://link.springer.com/book/10.1007\%2F978-94-017-1295-8

[4] Hellsten, M. (2002) Drag-Reducing Surfactants. Journal of Surfactants and Detergents, 5, 65-70.

[5] Saeki, T., Tokuhara, K. and Matsumuta, T. (2008) Development and Spread of Energy Saving Technology by Using Drag-reducing Additives. The Eighth Green and Sustainable Chemistry Award Awarded by the Minister of the Environment in Japan. http://www.jaci.or.jp/english/gscn/awards/aw20090902_01.html

[6] Kishimoto, A., Nishimura, K. and Kashiwagi, A. (2007) Drag Reduction Additive for Centralized Air-Conditioning of Buildings. The SCEJ Technical Achievement Award in 2007 Awarded by Society of Chemical Engineering, Japan. http://www.scej.org/en/awards/scej-award/scej-award-for-otd.html

[7] Gordon, R.J. and Balakrishnan, A. (1972) Vortex Inhibition: A New Viscoelastic Effect with Importance in Drag Reduction and Polymer Characterization. Journal of Applied Polymer Science, 16, 1629-1639.

http://onlinelibrary.wiley.com/doi/10.1002/app.1972.070160704/abstract

[8] Harwigsson, I. and Hellsten, M. (1996) Environmentally Acceptable Drag-Reducing Surfactants for District Heating and Cooling. Journal of the American Oil Chemists Society, 73, 921-928. https://doi.org/10.1007/BF02517996

[9] Zakin, J.L., Kawaguchi, Y., Talmon, Y. and Hart, D.J. (2006) Development of Practical Drag Reduction System for District Cooling Systems. NEDO Report, Registration Number: 2002EF001.

http://www.nedo.go.jp/content/100084667.pdf\#search='NEDO+Report\%2C+Registration+ Number\%3A+2002EF001

[10] Gravsholt, S. (1976) Viscoelasticity in Highly Dilute Aqueous Solutions of Pure Cationic Detergents. Journal of Colloid and Interface Science, 57, 575-577. https://doi.org/10.1016/0021-9797(76)90236-8

[11] Hyde, A.J. and Stevenson, D.M. (1969) The Effect of Organic Additives on Paraffin Chain Electrolyte Solutions. Part IV. Electrical Conductance Measurements on Solubilised Solutions of Hydrocarbons. Kolloid-Zeitschrift und Zeitschrift für Polymere, 232, 797-804. https://doi.org/10.1007/BF01500658

[12] Rao, U.R.K., Manohar, C., Valailokar, B.S. and Iyer, R.M. (1987) Micellar Chain Model for the Origin of the Visoelasticity in Dilute Surfactant Solutions. The Journal of Physical Chemistry, 91, 3286-3291. https://doi.org/10.1021/j100296a036

[13] Kato, M., Takahashi, T. and Shirakashi, M. (2006) Influence of Planar Elongation Strain on Flow-Induced Structure and Flow Instability of CTAB/Nasal Aqueous Solution. Nippon Kikai Gakkai Ronbunshu, B-hen, 72, 1935-1942. https://www.jstage.jst.go.jp/article/kikaib1979/72/720/72_720_1935/_pdf 
[14] Bogue, D.C. and Doughty, J.O. (1966) Comparison of Constitutive Equations for Viscoelastic Fluids. Industrial \& Engineering Chemistry Fundamentals, 5, 243-252.

[15] Kapoor, N.N., Kalb, J.W., Brumm, E.A. and Fredrickson, A.G. (1965) Stress-Relaxing Solids. Industrial \& Engineering Chemistry Fundamentals, 4, 186-194.

[16] Itoh, M., Tamano, S., Yokota, K. and Ninagawa, M. (2005) Velocity Measurement in Turbulent Boundary Layer of Drag-Reducing Surfactant Solution. Physics of Fluids, 17, Article ID: 075107. https://doi.org/10.1063/1.1979523

[17] Johansson, L., Lindblom, G., Gravsholt, S. and Norden, B. (1979) Viscoelastic Amphiphile Aqueous Solutions Studied by Linear Dichroism Spectroscopy. Journal of Colloid and Interface Science, 69, 358-361. https://doi.org/10.1016/0021-9797(79)90170-X

[18] Gravsholt, S. (1979) Rheopectic Behavior of Highly Dilute Viscoelastic Aqueous Detergent Solutions. Naturwissenschaften, 66, 263-264. https://doi.org/10.1007/BF00571610

[19] Angel, M., Hoffmann, H., Löbl, M., Reizlein, K., Thurn, H. and Wunderlich, I. (1984) From rodlike micelles to lyotropic liquid crystals. Progress in Colloid and Polymer Science, 69, 12-28.

[20] Imae, T., Hashimoto, K. and Ikeda, S. (1990) The Spinnability of Viscoelastic Solutions of Tetradecyl- and Hexadecyl-Trimethylammonium Salicylates. Colloid and Polymer Science, 268, 460-468. https://doi.org/10.1007/BF01411005

[21] Imae, T. (1990) Light Scattering of Spinnable, Viscoelastic Solutions of Hexadecyltrimethylammonium Salicylate. Journal of Physical Chemistry, 94, 5953-5959. https://doi.org/10.1021/j100378a063

[22] Imae, T. and Kohsaka, T. (1992) Size and Electrophoretic Mobility of Tetradecyltrimethylammonium Salicylate (C14TASal) Micelles in Aqueous Media. Journal of Physical Chemistry, 96, 10030-10035. https://doi.org/10.1021/j100203a081

[23] Hashimoto, K., Imae, T. and Nakazawa, K. (1992) The Viscoelasticity of Spinnable Solutions of Alkyltrimethylammonium Salicylates. Colloid and Polymer Science, 270, 249-258. https://doi.org/10.1007/BF00655477

[24] Imae, T., Kato, M. and Rutland, M. (2000) Forces between Two Glass Surfaces with Adsorbed Hexadecyltrimethylammonium Salicylate. Langmuir, 16, 1937-1942.

https://doi.org/10.1021/la990824y

[25] Alfaro, J., Landázuri, G., González-Álvarez, A., Macías, E.R., Fernandez, V., Shulz, P., Rodríguez, J. and Soltero, J. (2010) Phase and Rheological Behavior of the Hexadecyl(Trimethyl)Azanium, 2-Hydroxybenzoate/Water System. Journal of Colloid and Interface Science, 351, 171-179. https://doi.org/10.1016/j.jcis.2010.07.038

[26] Birdi, K.S. (1986) Determination of C.M.C. and Aggregation Numbers for Some Cationic Surfactants. Acta Chemica Scandinavica, 40A, 319-321.

https://doi.org/10.3891/acta.chem.scand.40a-0319

[27] Mukerjee, P. and Mysels, K.J. (1971) Critical Micellar Concentration of Aqueous Surfactant Systems. National Bureau of Standard, Washington.

[28] Basu Ray, G., Charkraborty, I., Ghosh, S., Moulik, S.P. and Palepu, R. (2005) Self-Aggregation of Alkyltrimethylammonium Bromides $\left(\mathrm{C}_{10^{-}}, \mathrm{C}_{12^{-}}, \mathrm{C}_{14^{-}}\right.$, and $\left.\mathrm{C}_{16} \mathrm{TAB}\right)$ and Their Binary Mixtures in Aqueous Medium: A Critical and Comprehensive Assessment of Interfacial Behavior and Bulk Properties with Reference to Two Types of Micelle Formation. Langmuir, 21, 10958-10967. https://doi.org/10.1021/la051509g

[29] Ribeiro, A.C.F., Lobo, V., Valente, A., Azvedo, E., Miguel, M. and Burrows, H. (2004) Transport Properties of Alkyltrimethylammonium Bromide Surfactants in Aqueous Solutions. Colloid and Polymer Science, 283, 277-283. 
https://doi.org/10.1007/s00396-004-1136-X

[30] Carpena, P., Aguiar, J., Bernaola-Galván, P. and Carnero Ruiz, C. (2002) Problems Associated with the Treatment of Conductivity-Concentration Data in Surfactant Solutions: Simulations and Experiments. Langmuir, 18, 6054-6058. https://doi.org/10.1021/la025770y

[31] Moulik, S.P., Haque, M.E., Jana, P.K. and Das, A.R. (1996) Micellar Properties of Cationic Surfactants in Pure and Mixed States. Journal of Physical Chemistry, 100, 701-708. https://doi.org/10.1021/jp9506494

[32] Garcfa-Mateos, I., Velázques, M.M. and Rodriguez, L. (1990) Critical Micelle Concentration Determination in Binary Mixtures of Ionic Surfactants by Deconvolution of Conductivity/Concentration Curves. Langmuir, 6, 1078-1083. https://doi.org/10.1021/la00096a009

[33] Evans, D.F., Allen, M., Ninham, B.W. and Fouda, A. (1984) Critical Micelle Concentrations for Alkyltrimethylammonium Bromides in Water from 25 to $160^{\circ} \mathrm{C}$. Journal of Solution Chemistry, 13, 87-101. https://doi.org/10.1007/BF00646042

[34] Rodriguez, A., Junquera, E., del Burgo, P. and Aicart, E. (2004) Conductometric and Spectrofluorimetric Characterization of the Mixed Micelles Constituted by Dodecyltrimethylammonium Bromide and A Tricyclic Antidepressant Drug in Aqueous Solution. Journal of Colloid and Interface Science, 269, 476-483. https://doi.org/10.1016/j.jcis.2003.09.028

[35] Czapkiewicz, J., Dlugolecka, M. and Bozena, T. (2004) 10-Methylacridinium Ion as a Fluorimetric Probe Measuring the Activity of Halide Anions in Aqueous Solutions of Cationic Surfactants. Journal of Colloid and Interface Science, 276, 227-230. https://doi.org/10.1016/j.jcis.2004.03.020

[36] Evans, D.F. and Wightman, P.J. (1984) Micelle Formation above $100^{\circ}$ C. Journal of Colloid and Interface Science, 86, 515-524. https://doi.org/10.1016/0021-9797(82)90096-0

[37] Charkraborty, T., Ghosh, S. and Moulik, S.P. (2005) Micellization and Related Behavior of Binary and Ternary Surfactant Mixtures in Aqueous Medium: Cetyl Pyridinium Chloride (CPC), Cetyl Trimethyl Ammonium Bromide (CTAB), and Polyoxyethylene (10) Cetyl Ether (Brij-56) Derived System. Journal of Physical Chemistry B, 109, 14813-14823. https://doi.org/10.1021/jp044580o

[38] Klevens, H.B. (1953) Structure and Aggregation in Dilute Solution of Surface Active Agents. Journal of the American Oil Chemists' Society, 30, 74-80.

https://doi.org/10.1007/BF02635002

[39] Ohlendorf, D., Interhat, W. and Hoffmann, H. (1986) Surfactant Systems for Drag Reduction: Physico-Chemical Properties and Rheological Behaviour. Rheologica Acta, 25, 468-486. https://doi.org/10.1007/BF01774397 
Submit or recommend next manuscript to SCIRP and we will provide best service for you:

Accepting pre-submission inquiries through Email, Facebook, LinkedIn, Twitter, etc. A wide selection of journals (inclusive of 9 subjects, more than 200 journals)

Providing 24-hour high-quality service

User-friendly online submission system

Fair and swift peer-review system

Efficient typesetting and proofreading procedure

Display of the result of downloads and visits, as well as the number of cited articles

Maximum dissemination of your research work

Submit your manuscript at: http://papersubmission.scirp.org/

Or contact snl@scirp.org 